\title{
Glucagon-like peptide-1 (GLP-1) improved diabetic lung fibrosis via AMPK and microRNA-27a (miR-27a)
}

\author{
Jia Liu ${ }^{1 \#}$, Xiaoyu Li ${ }^{1 \#}$, Shan Lu' ${ }^{1}$, Xiao Zheng ${ }^{2}$, Xiaohui Zhang ${ }^{3}$, Wei Zhao ${ }^{1}$ \\ ${ }^{1}$ NHC Key Laboratory of Hormones and Development, Tianjin Key Laboratory of Metabolic Diseases, Tianjin Medical University Chu Hsien-I \\ Memorial Hospital \& Tianjin Institute of Endocrinology, Tianjin, China; ${ }^{2}$ Wuhan Puren Hospital Affiliated Medical College of Wuhan University of \\ Science and Technology, Clinical of Endocrinology and Metabolism, Wuhan, China; ${ }^{3}$ Department of Nutrition, First Teaching Hospital of Tianjin \\ University of Traditional Chinese Medicine, Tianjin, China \\ Contributions: (I) Conception and design: W Zhao; (II) Administrative support: W Zhao; (III) Provision of study materials or patients: W Zhao; (IV) \\ Collection and assembly of data: J Liu, X Li; (V) Data analysis and interpretation: J Liu, W Zhao; (VI) Manuscript writing: All authors; (VII) Final \\ approval of manuscript: All authors. \\ \#These authors contributed equally to this work. \\ Correspondence to: Wei Zhao. NHC Key Laboratory of Hormones and Development, Tianjin Key Laboratory of Metabolic Diseases, Tianjin \\ Medical University Chu Hsien-I Memorial Hospital \& Tianjin Institute of Endocrinology, Tianjin Medical University, Tianjin, China. \\ Email: zhaowei800128@126.com.
}

Background: Extracellular matrix proliferation is an issue which leads to lung tissue damage in diabetes mellitus. Glucagon-like peptide-1 (GLP-1) analogues can improve the proliferation of extracellular matrix in diabetic pulmonary disease. In this study, we investigated the effect of GLP-1 on pulmonary fibrosis through the AMPK/microRNA-27a (miR-27a) pathway.

Methods: Human embryonic lung fibroblast (MRC-5) cells were cultured with a high-glucose medium, and were treated with miR-27a inhibitor, GLP-1 analogues, and AMPK inhibitor. Cell Counting Kit-8 (CCK8) detected the proliferation of MRC-5 cells. The fibrosis-related genes were analyzed, including Col-IV, fibronectin, NF- $\kappa \mathrm{B}$ p $65, \alpha$-SMA, and TGF- $\beta 1$. Bioinformatics and dual-luciferase reporter assays were used to identify the targets for miR-27a.

Results: Compared with the control group, the expression of miR-27a in the hyperglycemic group was significantly up-regulated $(\mathrm{P}<0.01)$ and the expression of peroxisome proliferator-activated receptor $\gamma$

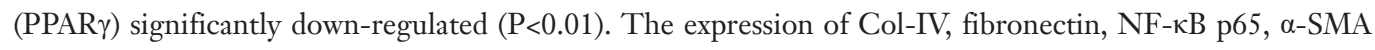
and TGF- $\beta 1$ increased significantly $(\mathrm{P}<0.01)$. The expression level of apoptosis factor caspase- 3 decreased significantly $(\mathrm{P}<0.01)$. MiR-27a inhibitor could reverse the expression of these proteins. The effect of GLP1 on miR-27a was time- and concentration-dependent. After pretreating MRC-5 cells via GLP-1, with or without compound C (AMPK inhibitor), the expression of miR-27a in the GLP-1 treated group was significantly lower than that in Vehicle group. The expression of miR-27a was increased after inhibition of the AMPK pathway. A predictive TargetScan algorithm showed that the PPAR $\gamma$ gene was a potential target of miR-27a. MiR-27a was also shown to target 3'-UTR of PPAR $\gamma$.

Conclusions: MiR-27a plays an important regulatory role in diabetic pulmonary fibrosis. GLP-1 could down-regulate the expression level of miR-27a by activating AMPK. Furthermore, the target gene PPAR $\gamma$ was up-regulated, consequently improving extracellular matrix proliferation in MRC-5 cells.

Keywords: Glucagon-like peptide-1 (GLP-1); lung fibrosis; diabetes mellitus; AMPK; miR-27a

Submitted Jan 11, 2021. Accepted for publication Mar 20, 2021.

doi: $10.21037 /$ atm-21-869

View this article at: http://dx.doi.org/10.21037/atm-21-869 


\section{Introduction}

Vascular damage is a fundamental physiological process that underpins chronic complications seen in diabetes mellitus. As the lungs have the largest capillary network in the human body, diabetes can accelerate lung function decline (1). In Type 2 diabetes mellitus, the decline of pulmonary function was 2-3 times faster than that in healthy adults, and the risk of pulmonary fibrosis was significantly higher $(\mathrm{OR}=4.06$, 95\% CI: 1.80-9.15) (2).

Proliferation of extracellular matrix is the key mechanism for lung tissue damage in diabetes mellitus. Glucagon-like peptide-1 (GLP-1) analogues have been widely used in the treatment of diabetes mellitus. There is increasing evidence that GLP-1 has an extrapancreatic effect on organ fibrosis. After 12 weeks of intervention with the GLP-1 analogue liraglutide in diabetic rats, the expression of collagen type (Col-) III in lung tissue of Type 2 diabetic rats was significantly decreased (3). In the highglucose condition, the expression of fibronectin and Col-III was decreased significantly after the intervention of GLP1 in MRC-5 cells (4). These results suggest that GLP-1 significantly improves proliferation of extracellular matrix in the diabetic lung, and that this improvement is unrelated to blood sugar control (5).

The microRNA-27a (miR-27a) family is highly expressed in lung and heart tissues. Kang et al. (6) found that after 3 weeks of hypoxic exposure (10\%), the lung tissue of C57BL/6 mice showed significantly increased expression of miR-27a, while the expression of peroxisome proliferatoractivated receptor $\gamma$ (PPAR $\gamma$ ) decreased. Over-expression of miR-27a could inhibit the expression of PPAR $\gamma$ (7). $\operatorname{PPAR} \gamma$ is expressed in various kinds lung cells, including alveolar macrophages, epithelial cells, fibroblasts, and vascular endothelial cells. PPAR $\gamma$ agonists can reduce the transformation of fibroblasts to myofibroblasts, and promote the transformation of fibroblasts into adipocytes, thereby inhibiting proliferation.

Our previous results showed that AMPK activation significantly inhibited expression of miR-27a (8). Miao et al. found that GLP-1 analogues can promote the proliferation of insulin $\beta$ cells through the $\mathrm{AMPK} / \mathrm{m}$ TOR signaling pathway (9). Ben-Shlomo et al. also found that GLP-1 can inhibit the formation of fatty liver through the AMPK pathway (10).

This study aims to further explain the correlations between miR-27a, AMPK, and MRC-5 cell activity. With MRC-5 cells as the research subject, the influence of GLP-
1 on the proliferation of the pulmonary extracellular matrix through $\mathrm{AMPK} / \mathrm{miR}-27$ a regulation is investigated.

We present the following article in accordance with the MDAR reporting checklist (available at http://dx.doi. org/10.21037/atm-21-869).

\section{Methods}

\section{Cell culture}

Human embryonic lung fibroblast (MRC-5) cellspurchased from Cell Culture Center of Chinese Academy of Medical Sciences (Beijing, China)—were cultured in low glucose Dulbecco's Modified Eagle Medium (DMEM) (GIBCO, Grand Island, NY) supplemented with $10 \%$ fetal bovine serum, $1 \%$ L-glutamine, $100 \mu \mathrm{g} / \mathrm{mL}$ penicillin, and $100 \mu \mathrm{g} / \mathrm{mL}$ streptomycin, and kept in humidified atmosphere containing $5 \% \mathrm{CO}_{2}$ at $37^{\circ} \mathrm{C}$.

\section{Cell transfection}

The miR-27a gain-of-function study was performed using miR-27a mimics, inhibitor (50 nM, GenePharma, Shanghai, China) and their negative control $(50 \mathrm{nM})$, respectively, on the MRC-5 fibroblast. The miR-27a mimics sequence is 5'-UUCACAGUGGCUAAGUUCCGC-3'. The miR-27a inhibitor sequence is 5'-GCGGAACUUAGCCACUGUGAA-3'. MRC-5 cells were transfected using Lipofectamine ${ }^{\mathrm{TM}}$ RNAiMax (Invitrogen, Carlsbad, CA, USA), according to the manufacturer's instructions. The relative level of miR-27a in transfected MRC-5 cells was detected by quantitative reverse transcription polymerase chain reaction (qRT-PCR).

\section{qRT-PCR}

Total RNA was extracted from cells using Trizol reagent (Invitrogen, CA, USA) or miRNeasy Mini Kit (QIAGEN) according to manufacturer's instructions. RNA quality and quantity were measured using a nanodrop spectrophotometer (ND-1000, Nanodrop Technologies, MA, USA). RNA integrity was determined by gel electrophoresis. The samples were reverse transcribed to cDNA using EzOmics ${ }^{\mathrm{TM}} \mathrm{SYBR}$ qPCR Kit (Biomics, BK2200, Nantong, China). The expression of miRNA was quantified with qRT-PCR using SYBR ${ }^{\circledR}$ Premix Ex $\operatorname{Taq}^{\mathrm{TM}}$ (Takara, RRoc41A, Kusatsu, Japan). The 
relative expression of miR-27a was calculated using the expression of U6 small nuclear RNA as the reference. The sequence-specific forward primers for mature miR27a and U6 internal control were as follows: for miR27a, 5'-CGCATTCACAGTGGCTAAG-3'; and for U6, 5'-TGCGGGTGCTCGCTTCGGC-3'.

\section{Collection of cell lysate}

MRC-5 cells were treated with liraglutide, compound C, or miR-27a inhibitor. Cultured MRC-5 cells were then harvested and extracted in RIPA lysate buffer.

\section{Western blotting}

Protein samples were separated by SDS-PAGE gels and transferred to nitrocellulose membrane. The membranes were washed with Tris-buffered saline supplemented with $0.05 \%$ NP-40 and 5\% non-fat dry milk for 30 minutes at $37{ }^{\circ} \mathrm{C}$. Immunoblotting was performed following standard procedures, and the signals were detected using chemiluminescence reagents (Syngene). Gene Tool analyzes the protein expression of the fibrosisrelated genes. Primary antibodies were directed against: PPAR $\gamma$ (1:1,000, Proteintech, 16643-1-AP), ColIV (1:1,000, Proteintech, 55131-1-AP), Fibronectin (1:1,000, Proteintech, 15613-1-AP), NF-кB p65 (1:2,000, Proteintech, 10745-1-AP), $\alpha$-SMA (1:4,000, Proteintech, 14395-1-AP), TGF- $\beta 1$ (1:2,000, Proteintech, 21898-1AP), caspase-3 (1:1,000, CST, \#5140) and $\beta$-actin $(1: 4,000$, Proteintech, 20536-1-AP).

\section{Cell counting kit-8 (CCK-8) detected the proliferation of MRC-5 cells}

Cell proliferative rates of MRC-5 cells lines were evaluated with the CCK- 8 assay (MedChemExpress, China) according to the manufacturer's instructions. The above glioma cells were treated with 10, 100, 1,000 nM liraglutide respectively, and plated into 96 -well plates $\left(2 \times 10^{3}\right.$ cells per well) containing media. The MRC-5 cells were then cultured for 24 hours and incubated with CCK- 8 reagent at a final concentration of $10 \mu \mathrm{L} / \mathrm{mL}$ for 4 hours at $37^{\circ} \mathrm{C}$. Before reading the plate, it was mixed gently on an orbital shaker for 1 minute to ensure homogeneous distribution of color. The absorbance was then measured at $450 \mathrm{nM}$ with a Thermomax Microplate Reader (Molecular Devices, Sunnyvale, CA, USA). Each experiment was repeated three times.

\section{Statistical analysis}

Results were presented as a mean \pm standard deviation. Statistical analyses were assessed using a Student's $t$-test between two groups and one-way ANOVA with multiple groups. All analyses were performed with SPSS 19.0 (SPSS Inc., USA) and a value of $\mathrm{P}<0.05$ was considered statistically significant.

\section{Results}

\section{Hyperglycemia promoted the expression of miR-27a and decreased the expression of fibrosis-related genes in human embryonic lung fibroblast (MRC-5) cells}

In this study, MRC-5 cells were selected as the research subject. MRC-5 cells were cultured in three groups: normal control group (NC, DMEM medium containing $5 \mathrm{mM}$ of glucose), hyperosmotic group (M, DMEM medium containing mannitol equal to $25 \mathrm{mM}$ glucose group's osmotic pressure), and hyperglycemic group (HG, DMEM medium containing $25 \mathrm{mM}$ of glucose). qRT-PCR was used to detect the expression of miR-27a in the three groups of cells after 48 hours of culture (Figure 1A). Compared with normal control group, there was no difference in the expression of miR-27a in hyperosmotic group, while the expression of miR-27a in hyperglycemic group was significantly upregulated $(\mathrm{P}<0.01)$.

$\operatorname{PPAR} \gamma$ plays an important role in the pathogenesis of organ fibrosis. We detected the mRNA expression of PPAR $\gamma$ in all three groups of cells (Figure 1B). Compared with the normal control group, the expression of PPAR $\gamma$ in the hyperosmotic group was not different, while the expression of PPAR $\gamma$ in the hyperglycemic group was significantly down-regulated $(\mathrm{P}<0.01)$.

Extracellular matrix proliferation is a key problem in diabetic lung damage. We further examined the expression of fibrosisrelated genes. The expression of PPAR $\gamma$ protein decreased significantly in cells cultured with high-glucose medium. Accordingly, compared with control group, the expression of extracellular matrix-related genes Col-IV and fibronectin, the expression of extracellular matrix synthesis pathwayrelated genes NF- $\mathrm{KB}$ p 65 , and the expression of fibroblast differentiation and proliferation-related genes $\alpha$-SMA and TGF- $\beta 1$ increased significantly. The expression of caspase-3 protein decreased significantly $(\mathrm{P}<0.01$, Figure $1 C, D)$. 
A

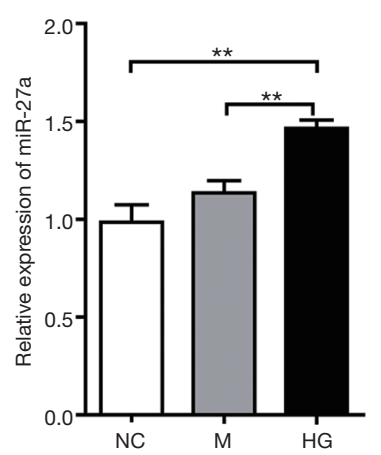

B

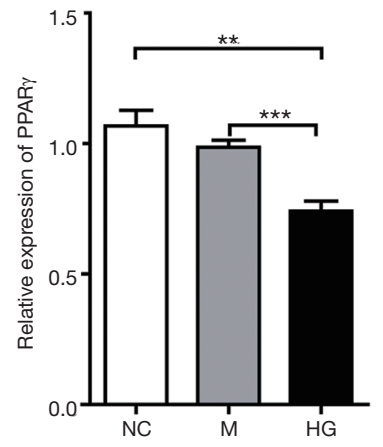

C

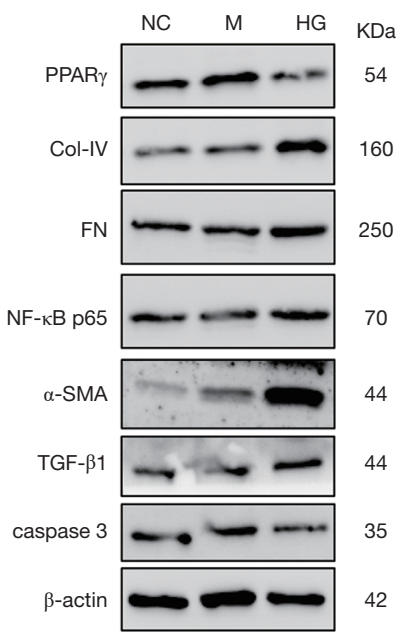

D
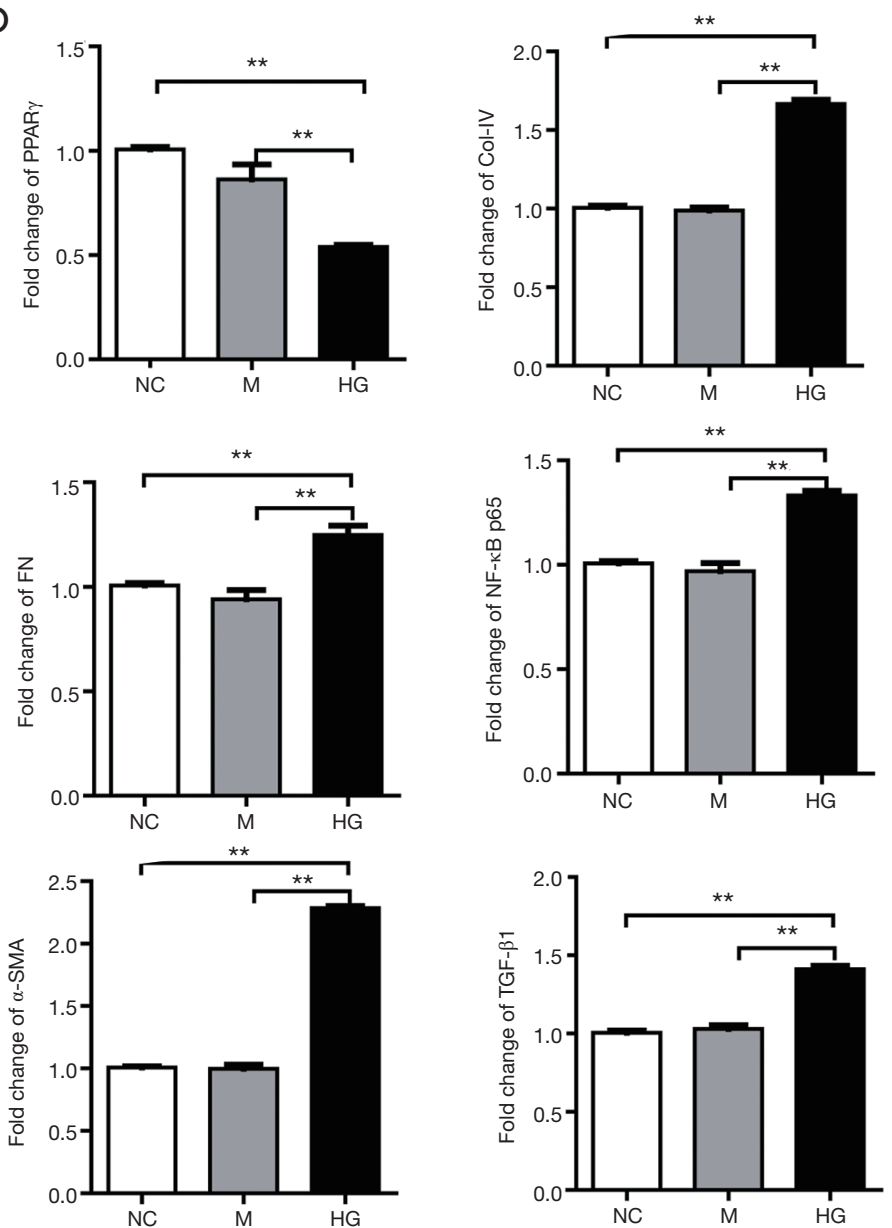

Figure 1 Hyperglycemia promoted the expression of miR-27a and decreased the expression of fibrosis-related genes in MRC-5 human embryonic lung fibroblasts. (A) MRC-5 cells were cultured in three groups: normal control group (NC, DMEM medium containing 5 $\mathrm{mM}$ of glucose), hypertonic group (M, DMEM medium containing mannitol equal to $25 \mathrm{mM}$ glucose group's osmotic pressure), and hyperglycemic group (HG, DMEM medium containing $25 \mathrm{mM}$ of glucose). qRT-PCR was used to detect the expression of miR-27a in three groups of cells after 24 hours of culture. (B) qRT-PCR was u-sed to detect the expression of PPAR $\gamma$ in the three groups of cells after 24 hours of culture. (C,D) Western blotting detected the expression of Col-IV, fibronectin, NF-кB p65, $\alpha$-SMA, TGF- $\beta 1$ and caspase-3. ${ }^{* *} \mathrm{P}<0.01 ;{ }^{* *} \mathrm{P}<0.001$. miR-27a, microRNA-27a; PPAR $\gamma$, Peroxisome proliferator-activated receptor $\gamma$; Col-IV, type IV collagen; $\alpha$-SMA, alpha-smooth muscle actin; TGF- $\beta 1$, transforming growth factor-beta 1 ; FN, fibronectin MRC-5, human embryonic lung fibroblasts; qRTPCR, quantitative reverse transcription polymerase chain reaction. 
A
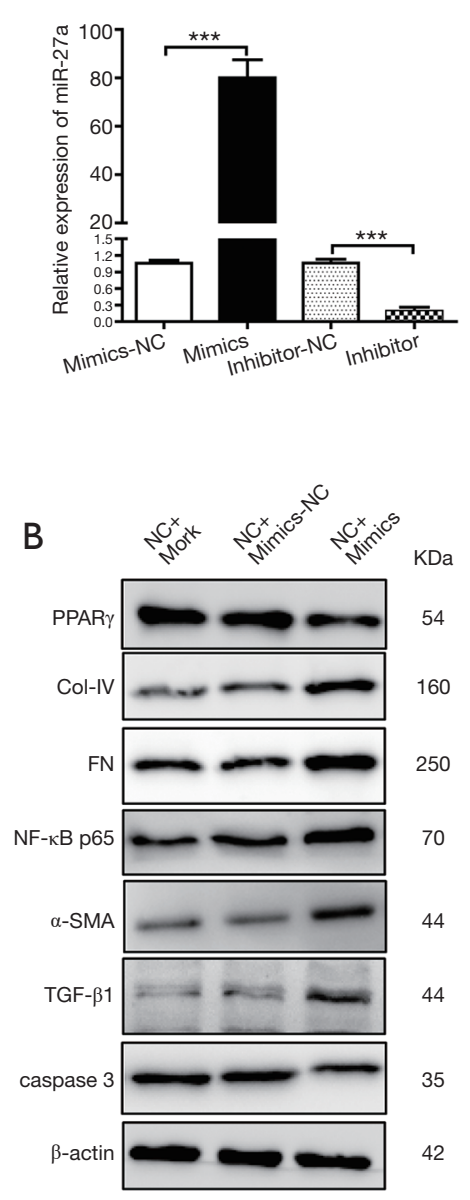

C
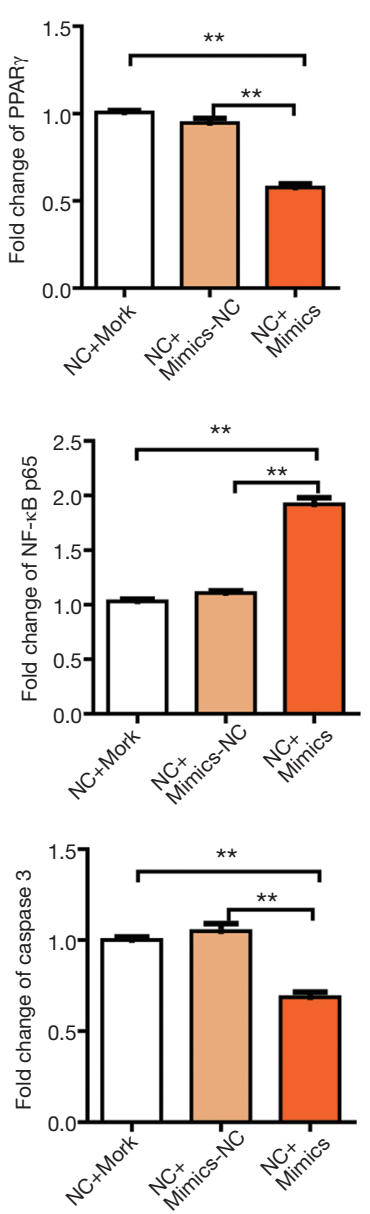
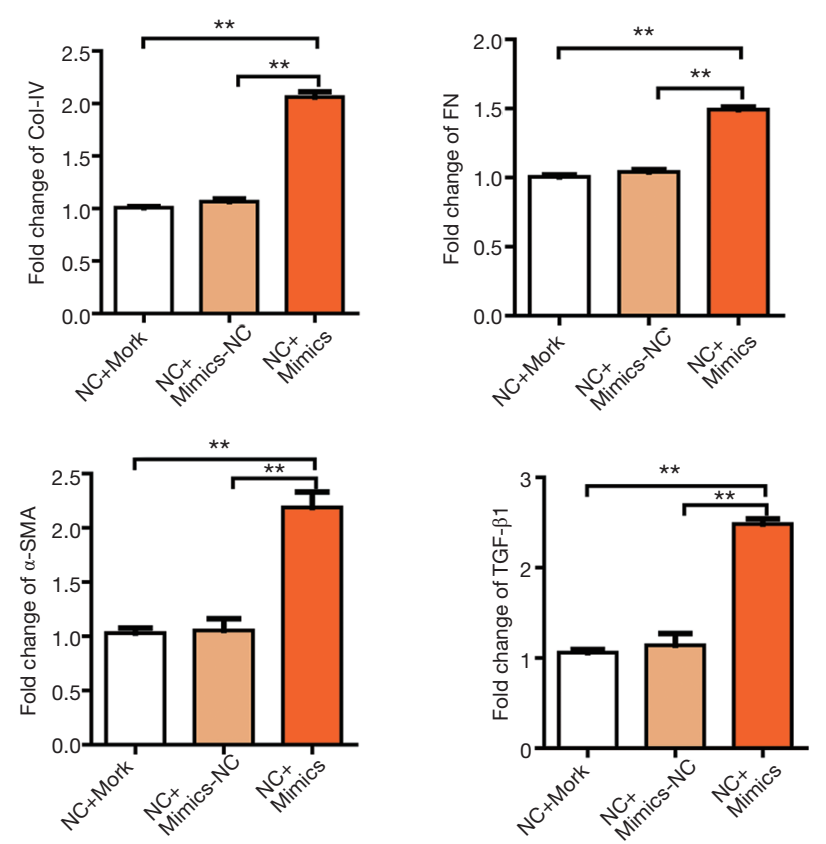

Figure 2 The effects of over-expression the expression of miR-27a on fibrosis-related genes expression in MRC-5 cells (A) qRT-PCR was used to detect the expression of miR-27a after transfected by miR-27a mimics or miR-27a inhibitor. (B) qRT-PCR was used to detect the expression of PPAR $\gamma$ after transfected by miR-27a mimics. (C) Western blotting detected the expression of Col-IV, fibronectin, NF- $\mathrm{kB}$ p65, $\alpha$-SMA, TGF- $\beta 1$ and caspase- 3 after transfected by miR-27a mimics. ${ }^{* *} \mathrm{P}<0.01,{ }^{* * *} \mathrm{P}<0.001$. miR-27a, microRNA-27a; mimics-NC, mimics normal control group; mimics: miR-27a mimics group; inhibitor-NC, inhibitor normal control group; inhibitor: miR-27a inhibitor group; PPAR $\gamma$, Peroxisome proliferator-activated receptor $\gamma$; Col-IV, type IV collagen; FN, fibronectin; $\alpha$-SMA, alpha-smooth muscle actin; TGF- $\beta 1$, transforming growth factor-beta $1 ;$ MRC-5, human embryonic lung fibroblasts; qRT-PCR, quantitative reverse transcription polymerase chain reaction.

\section{The effects of miR-27a over-expression or inbibited expression on fibrosis-related genes expression in MRC-5 cells}

In the hyperglycemic condition, the expression of miR27a and PPAR $\gamma$ in MRC-5 cells changed negatively. Kang et al. (6) found that PPAR $\gamma$ 3'-UTR had a binding site of miR-27a in pulmonary vascular cells, which confirmed that PPAR $\gamma$ was the target gene of miR-27a. We speculate that miR-27a directly regulated pulmonary extracellular matrix proliferation by its target PPAR $\gamma$. MRC-5 cells were transfected with miR-27a mimics, and the expression of miR-27a and PPAR $\gamma$ were detected by qRT-PCR. miR27 a mimics significantly increased the level of miR-27a and inhibited the expression of PPAR $\gamma$ (Figure 2A,B). Compared with the normal control group, the expression of Col-IV, fibronectin, NF- $\kappa \mathrm{B}$ p $65, \alpha-\mathrm{SMA}$ and TGF- $\beta 1$ increased significantly. The expression of caspase-3 protein decreased significantly $(\mathrm{P}<0.01$, Figure $2 C, D)$.

We further examined the effects of miR-27a inhibitor 
A

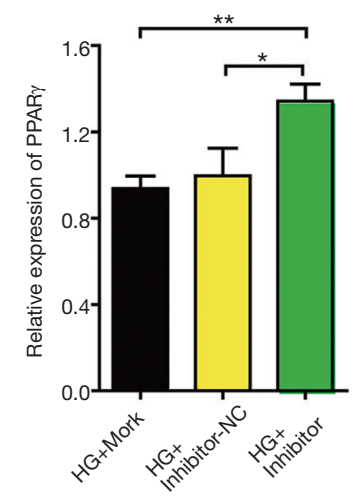

B

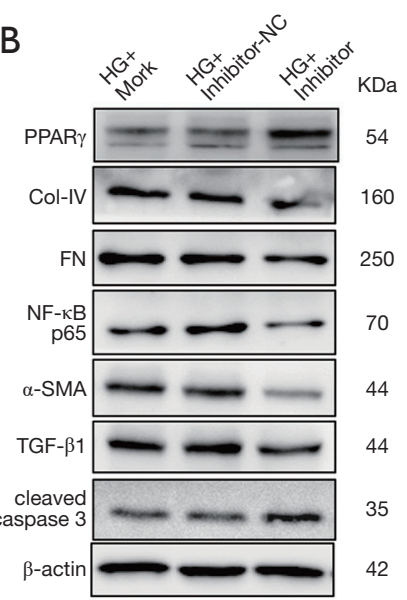

C
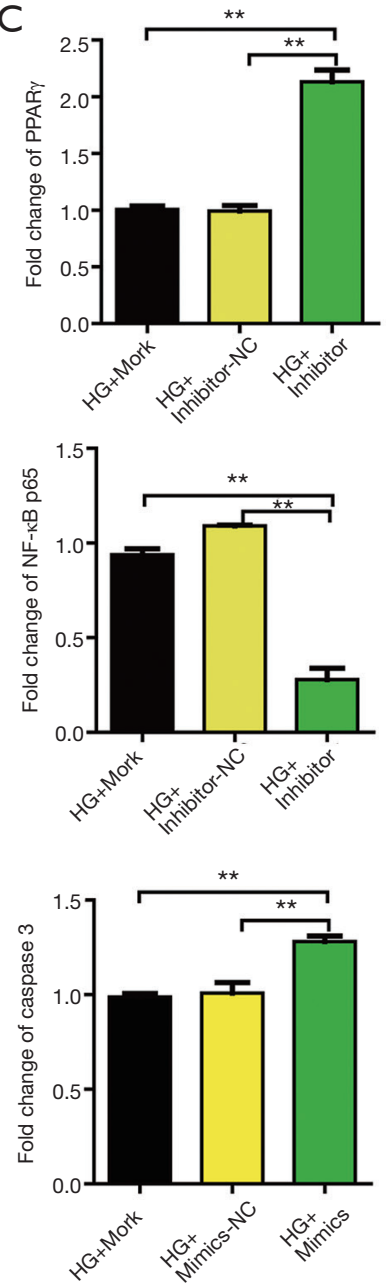
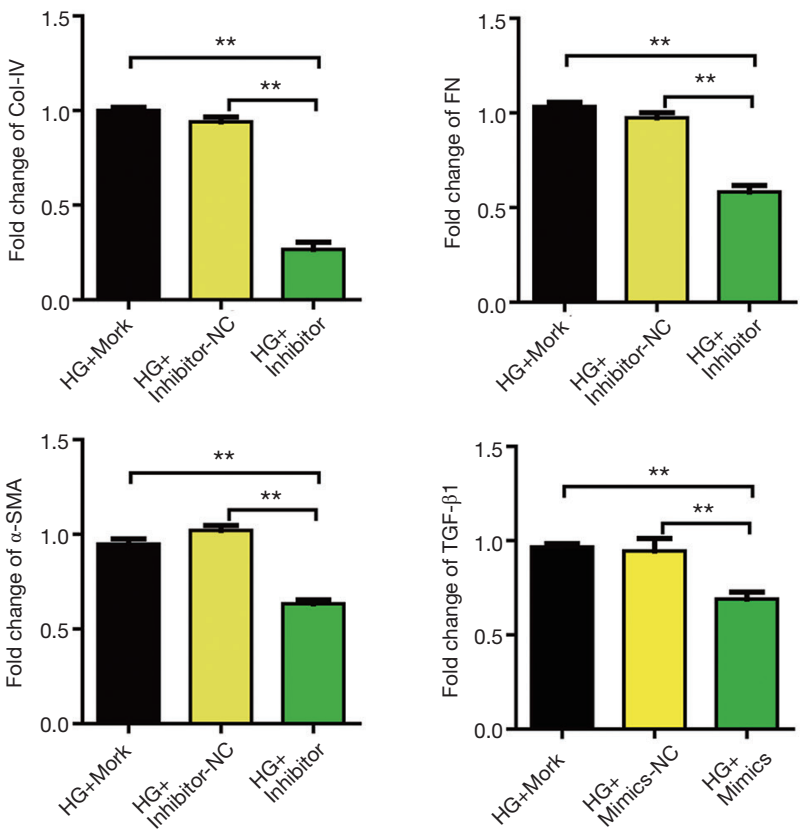

Figure 3 The effects of GLP-1 inhibited the expression of miR-27a on fibrosis-related genes expression in MRC-5 cells (A) qRT-PCR was used to detect the expression of PPAR $\gamma$ after transfected by miR-27a inhibitor. (B) and (C) Western blotting detected the expression of ColIV, fibronectin, NF- $\kappa B$ p $65, \alpha$-SMA, TGF- $\beta 1$ and caspase- 3 after transfected by miR-27a inhibitor. ${ }^{*} \mathrm{P}<0.05,{ }^{* *} \mathrm{P}<0.01$. PPAR $\gamma$, peroxisome proliferator-activated receptor $\gamma$; HG, hyperglycemic group; inhibitor-NC, inhibitor normal control group; inhibitor: miR-27a inhibitor group; Col-IV, type IV collagen; FN, fibronectin; $\alpha$-SMA, alpha-smooth muscle actin; TGF- $\beta 1$, transforming growth factor-beta 1 ; miR27a, microRNA-27a; MRC-5, human embryonic lung fibroblasts; qRT-PCR, quantitative reverse transcription polymerase chain reaction.

on these genes' expression in MRC-5 cells. After 48 hours of transfection, MRC-5 cells were cultured in high-glucose medium and transfected by miR-27a inhibitor for 24 hours. $\operatorname{PPAR} \gamma$ protein expression in high-glucose plus inhibitor group was significantly up-regulated $(\mathrm{P}<0.01)$ compared with normal control group (Figure $3 A$ ). Further collecting proteins from the three groups of cells showed that in the high-glucose condition, down-expression of miR-27a in MRC-5 cells significantly inhibited the protein expression of Col-IV and fibronectin, NF- $\mathrm{kB}$ p $65, \alpha$-SMA and TGF- $\beta 1$, and increased the expression of caspase-3 and MMP-2 (Figure 3B,C).
The results suggested that the expression of genes related to fibrosis in MRC-5 cells can be altered by altering the level of miR-27a.

\section{GLP-1 promoted the expression of miR-27a and the} AMPK signaling patbway was involved in the biological process of GLP-1 regulating miR-27a expression in MRC5 cells

Our previous studies shown that GLP-1 improved the proliferation of extracellular matrix in diabetic lung 
A

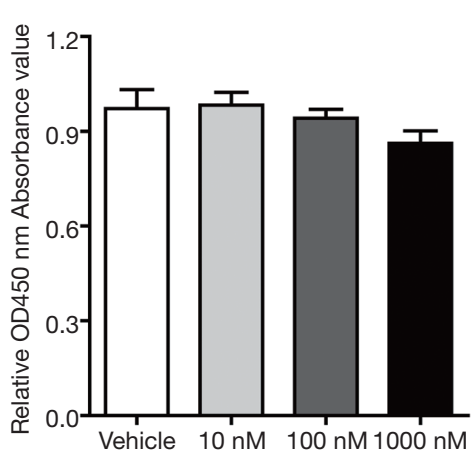

C

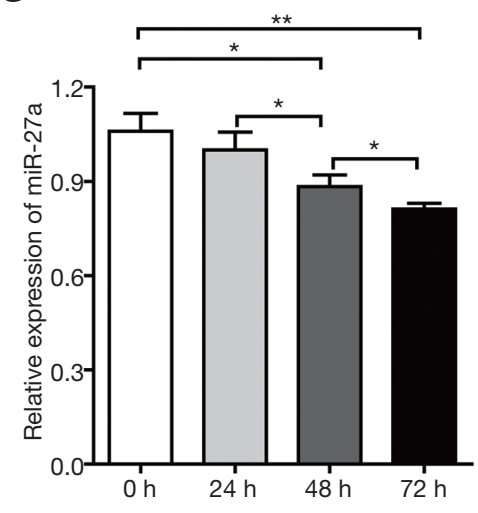

B

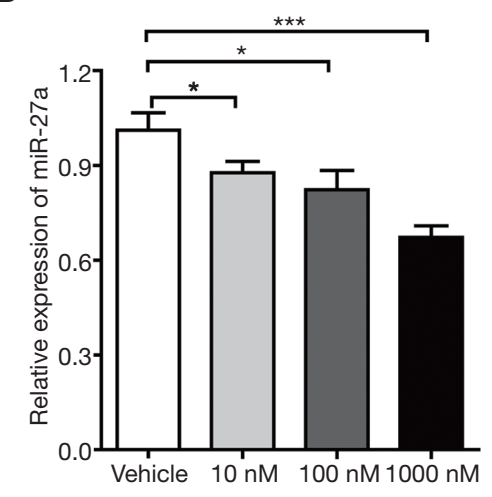

D

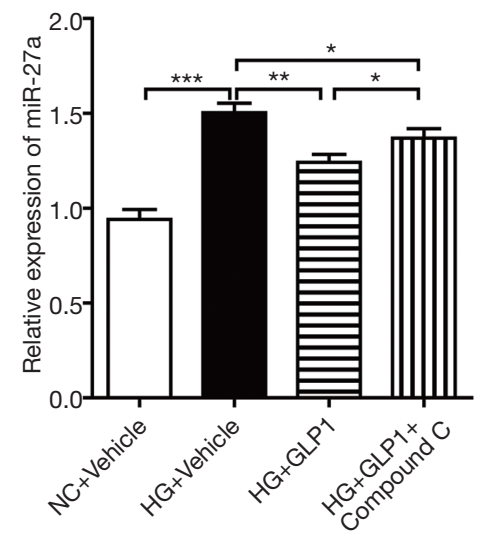

Figure 4 GLP-1 repressed the expression of miR-27a and AMPK signaling pathway was indeed involved in the biological process of GLP1 regulating miR-27a expression in MRC-5 cells. (A) CCK-8 detection of cell proliferation between 10, 10, 1,000 nM GLP-1 treatment group and control group. (B) qRT-PCR was used to detect the expression of miR-27a in MRC-5 cells treated with 10, 100, 1,000 nM GLP1 respectively. (C) qRT-PCR was used to detect the expression of miR-27a in MRC- 5 cells treated with $10 \mathrm{nM}$ GLP-1 for 24,48 or 72 hours respectively. (D) qRT-PCR was used to detect the expression of miR-27a in MRC-5 cells treated with or without compound C. ${ }^{*} \mathrm{P}<0.05$, ${ }^{* *} \mathrm{P}<0.01,{ }^{* * *} \mathrm{P}<0.001$. miR-27a, microRNA-27a; NC, normal control group; HG, hyperglycemic group; GLP-1, Glucagon-like peptide-1; MRC-5, human embryonic lung fibroblasts; CCK-8, Cell Counting Kit-8; qRT-PCR, quantitative reverse transcription polymerase chain reaction.

significantly; however, the mechanism remains unclear. We first examined the effects of different concentrations of GLP-1 on the proliferation of MRC-5 cells. There were no differences in cell proliferation between 10, 100, 1,000 nM treatment groups and the control group (Figure 4A).

We further examined the expression of miR-27a in MRC5 cells treated with different concentrations of GLP-1. MRC-5 cells were treated with 10,100 and 1,000 nM GLP-1 for 48 hours respectively. The expression of miR-27a was down-regulated in 10 and $100 \mathrm{nM}$ groups compared with the control group $(\mathrm{P}<0.05)$, and significantly down-regulated in the 1,000 nM GLP-1 intervention group $(\mathrm{P}<0.01)$. It is suggested that the expression of miR-27a was related to the concentration of GLP-1 (Figure 4B).

MRC-5 cells were cultured in DMEM with $25 \mathrm{mM}$ glucose and were treated with $10 \mathrm{nM} \mathrm{GLP-1}$ for 24,48 or 72 hours respectively. There was no significant difference in the expression of miR-27a between the 24-hour treatment group and the control group. After 48 hours of treatment, the expression of miR-27a decreased $(\mathrm{P}<0.05)$, and the 
expression of miR-27a decreased further $(\mathrm{P}<0.01)$ in the 72-hour treatment group (Figure 4C). Statistical analysis shows that the change of miR-27a expression was correlated with the treatment time of GLP-1.

A large number of studies suggested that GLP-1 played its biological role through the AMPK signaling pathway. Hence, we endeavored to determine whether the AMPK signaling pathway is also involved in GLP-1's regulation of miR-27a expression in MRC-5 cells. We pretreated the MRC-5 cell with GLP-1 analogue; this showed that the expression of miR-27a in GLP-1 group was significantly lower than that in Vehicle group. We then treated MRC-5 cells with compound C (AMPK inhibitor) before supplying them with GLP-1. The expression of miR-27a increased significantly after inhibition of AMPK signal, while it was still lower than that in Vehicle group. It was indicated that inhibition of AMPK signal could not completely relieve the inhibitory effect of GLP-1 on miR-27a expression (Figure 4D). These results suggested that AMPK signaling pathway was indeed involved in the biological process of GLP-1's regulation of miR-27a expression in MRC-5 cells; however, GLP-1 may also regulate the expression of miR27 a through other additional signaling pathways.

In conclusion, the results suggest that GLP-1 may up-regulate the expression of PPAR $\gamma$ by inhibiting the expression of miR-27a, thus improving the accumulation of extracellular matrix in the diabetic lung.

\section{Discussion}

Chronic complications of diabetes mellitus may cause of death and disability. The lung is a target organ of pathology in diabetes mellitus and epidemiological studies have shown that diabetic patients have certain restrictive ventilation dysfunction, diffusion dysfunction and small airway dysfunction. Compared with non-diabetic patients, forced vital capacity (FVC), forced expiratory volume in the first second (FEV1) and diffusing capacity of carbon monoxide $\left(\mathrm{DL}_{\mathrm{CO}}\right)$ is reduced by $10-30 \%$ in diabetic patients with no smoking history and lung diseases. Therefore, diabetes in patients with acute or chronic heart or lung diseases may lead to severe respiratory failure (11). Exploring the prevention and treatment strategies for lung damage in diabetic patients will help to improve the clinical prognosis in this population.

Mexican case-control study showed that T2DM is the most important independent risk factor associated with pulmonary fibrosis (12). It has been shown that alveolar epithelial cells and the endothelial capillary basal lamina are significantly thicker in diabetic patients than in control subjects (13). Diabetes mellitus significantly increases mortality in idiopathic pulmonary fibrosis patients (14). Advanced glycation end products accumulation in the lung due to hyperglycemia may increase lung oxidative stress, resulting in lung fibrotic changes (15). Hyperglycemia induces oxidative stress, reactive oxygen species and reactive nitrogen species generation, and impairment of the capacity of the antioxidative defense system are the major causes of type 1 diabetes mellitus-induced lung fibrosis (16). Hyperinsulinemia, a major feature of type 2 diabetes mellitus, increases collagen deposition in the lungs and stimulates airway hyperresponsiveness through increasing contractile effects on airway smooth muscle cells (17).

Pathological extracellular matrix proliferation is a key change seen in lung damage in diabetes mellitus patients. In our previous research, we found that the alveolar capillary basement membrane was diffusely thickened in lungs of Type 2 diabetes mellitus patients and rabbits $(18,19)$. $\operatorname{PPAR} \gamma$ plays an important role in the mechanism of organ fibrosis. PPAR $\gamma$ also directly inhibits the expression of NF$\kappa \mathrm{B}$, regulates the expression of matrix metalloproteinases (MMP-9) and MMP-2 at the gene level by interacting with $\mathrm{NF}-\kappa \mathrm{B}$, and reduces the expression of connective tissue growth factor (CTGF) (7). PPAR $\gamma$ agonists also significantly inhibit the expression of TGF- $\beta 1 /$ Smad and TGF- $\beta 1 /$ JNK signal transduction pathways induced by extracellular matrix proliferation $(20,21)$. The number of fibroblasts and the expression of $\alpha$-SMA, fibronectin, Col-I, and Col-III in lung tissue of spontaneous type 2 diabetic OLETF rats have been shown to increase significantly (22). Compared with the normal control group, the expression of PPAR $\gamma$ protein in MCF-5 cells in the high-glucose group was significantly down-regulated $(\mathrm{P}<0.01$, see Figures 3 and 4$)$. Furthermore, the expression of extracellular matrixrelated genes Col-IV and fibronectin, the expression of extracellular matrix synthesis pathway related genes NF$\kappa \mathrm{B}$ p65, and the expression of $\alpha$-SMA and TGF- $\beta 1$ related to differentiation and proliferation of fibroblasts were significantly increased. The expression of apoptosis-related gene caspase- 3 decreased significantly.

miRNAs inhibited the expression of the target gene by specifically recognizing the corresponding target site on the target gene 3'UTR and binding to it by base complement pairing. Kang et al. found that the expression of miR-27a in lung tissue of C57BL/6 mice increased after exposure to hypoxia $(10 \%)$ for 3 weeks, while the expression of 
PPAR $\gamma$ decreased significantly. Over-expression of miR-27a inhibited the expression of $\operatorname{PPAR} \gamma$, and luciferase reporter gene test confirmed that PPAR $\gamma$ was the target gene of miR-27a (Figure 1). It is speculated that miR-27a may play an important role in the proliferation of extracellular matrix in diabetic lung. Compared with the normal control group, the expression of miR-27a in the high-glucose group was significantly upregulated $(\mathrm{P}<0.01)$. Under the high-glucose condition, the expression of miR-27a and PPAR $\gamma$ in MRC5 cells showed a reverse relationship, and the expression of Col-IV, fibronectin, NF- $\kappa \mathrm{B}$ p $65, \alpha$-SMA, and TGF- $\beta 1$ were also changed accordingly. We speculated that miR27 a regulated the proliferation of extracellular matrix in the lung by targeting PPAR $\gamma$. We then used miR-27a mimics and inhibitor transfected MRC-5 cells cultures with highglucose medium. Over-expression of miR-27a inhibited the expression of extracellular matrix-related genes Col-IV and fibronectin protein, decreased the expression of extracellular matrix synthesis pathway related gene NF- $\mathrm{KB}$ p65 protein, down-regulated the expression of $\alpha$-SMA and TGF- $\beta 1$ proteins, and promoted the expression of apoptosis-related genes caspase- 3 and MMP-2 protein (Figure 2). These results suggested that the expression of extracellular matrix proliferation-related genes can be changed by regulating the expression of miR-27a in MRC-5 cells at high glucose levels.

GLP-1 analogues have been widely used in hypoglycemic therapy for diabetes mellitus. Tang et al. (23) observed that the thickness of the alveolar capillary basement membrane in OLETF rats decreased significantly after GLP-1 intervention. After GLP-1 intervention in MRC5 cultured in high-glucose medium, the expression of fibronectin, Col-III in MRC-5 cells decreased significantly. The results suggested that GLP-1 significantly improved the proliferation of extracellular matrix in diabetic lung; however, the exact mechanism for this was unclear.

After 8 weeks of intervention with GLP-1 analogues in $\mathrm{db} / \mathrm{db}$ mice, it was found that the thickening of renal capillary basement membrane, renal TGF- $\beta 1$ and Col-IV expression in $\mathrm{db} / \mathrm{db}$ mice were significantly reduced, but this improvement was not related to blood glucose control. It is suggested that GLP-1 may improve the proliferation of extracellular matrix in the diabetic lung through a glucoseindependent way. MRC-5 cells were treated with $10 \mathrm{nM}$ GLP-1 for 24, 48 or 72 hours, respectively. Compared with the control group, there was no difference in the expression of miR-27a in the 24-hour treatment group. The expression of miR-27a in MRC-5 cells was significantly down-regulated in the 48- and 72-hour treatment groups $(\mathrm{P}<0.01)$. MRC-5 cells were then treated with 10,100 or 1,000 nM GLP-1 for 48 hours. The expression of miR$27 \mathrm{a}$ in all of the three groups was significantly downregulated $(\mathrm{P}<0.01)$. It is suggested that the effect of GLP1 on the expression of miR-27a is time- and concentrationdependent. Thus, GLP-1 may upregulate the expression of PPAR $\gamma$ via down-regulated miR-27a, leading to improved proliferation of extracellular matrix in the diabetic lung. Furthermore, we used CCK- 8 to detect the effect of GLP1 on the proliferation of MRC-5 cells. There was no significant difference in cell proliferation level between the four groups.

The function of GLP-1 is mediated by the GLP-1 receptor. GLP-1 activates the G $\alpha$ subunit by binding to its receptor, thus activating adenylate cyclase, increasing intracellular cyclic adenosine monophosphate (cAMP) level, and activating protein kinase A (PKA). Foreign studies have found that the GLP-1 analogue liraglutide activated AMPK in mouse muscle cells and regulated the translocation of the glucose cotransporter 4 (GLUT4) in mouse muscle cells (24). BenShlomo et al. also found that GLP-1 inhibited the formation of fatty liver through the AMPK pathway (10). It was shown that activation of AMPK significantly inhibited the expression of the miR-27 a family in primary cultured hepatocytes in C57BL/6 mice (25). So we expected to determine whether the AMPK signaling pathway was also involved in the biological process of GLP-1 regulating miR-27a expression in MRC-5 cells.

MRC-5 cells were treated with GLP-1 analogues. Compared with the control group, the expression of miR$27 \mathrm{a}$ in the GLP-1 intervention group was significantly reduced. Although expression of miR-27a increased in compound $\mathrm{C}$ pretreated group, it did not reach the control group level. It was suggested that inhibition of AMPK expression could not completely relieve the inhibitory effect of GLP-1 on miR-27a expression. These results suggested that the AMPK signaling pathway is involved in the biological process of GLP-1, regulating miR-27a expression in MRC-5 cells; however, GLP-1 may also regulate the expression of miR-27a through other signaling pathways.

In this paper, we confirmed that high glucose promoted the expression of miR-27a, inhibited the expression of PPAR $\gamma$, increased the expression of extracellular matrixrelated genes, Col-IV and fibronectin, and extracellular matrix synthesis pathway related gene, NF-kB p65, and increased expression of differentiation and proliferationrelated genes $\alpha$-SMA and TGF- $\beta 1$ in human embryonic 


\section{Page 10 of 11}

lung fibroblasts. The expression of apoptosis-related gene caspase-3 was significantly decreased. miR-27a inhibitor reduced miR-27a expression and reversed all of the above process. It was suggested that miR-27a played an important role in the process of MRC-5 cell fibrosis induced by high glucose. We then treated MRC-5 cells with different concentrations of GLP-1 at different times, which suggested that the effect of GLP-1 on miR-27a expression was timeand concentration- dependent. GLP-1 may play its role via the energy center AMPK. Investigations using MRC-5 cells that were pretreated with AMPK antagonist and treated with GLP-1 suggested that the AMPK signaling pathway is involved in the biological process of GLP-1's regulation of miR-27a expression in MRC-5 cells, and that GLP-1 may also regulate the expression of miR-27a through other signaling pathways.

\section{Acknowledgments}

Funding: This work was supported by grants from the National Science Foundation of Tianjin (16JCYBJC26800, 18JCYBJC93300, 18JCZDJC35500), Tianjin Health Commission Science and Technology Talent Cultivation Project (2010KZ89), and Scientific Research Funding of Tianjin Medical University Chu Hsien-I Memorial Hospital (2009DX02).

\section{Footnote}

Reporting Checklist: The authors have completed the MDAR reporting checklist. Available at http://dx.doi.org/10.21037/ atm-21-869

Data Sharing Statement: Available at http://dx.doi. org/10.21037/atm-21-869

Conflicts of Interest: All authors have completed the ICMJE uniform disclosure form (available at http://dx.doi. org/10.21037/atm-21-869). The authors have no conflicts of interest to declare.

Etbical Statement: The authors are accountable for all aspects of the work in ensuring that questions related to the accuracy or integrity of any part of the work are appropriately investigated and resolved.

Open Access Statement: This is an Open Access article distributed in accordance with the Creative Commons
Liu et al. GLP-1 improved diabetic lung fibrosis via miR-27a/AMPK

Attribution-NonCommercial-NoDerivs 4.0 International License (CC BY-NC-ND 4.0), which permits the noncommercial replication and distribution of the article with the strict proviso that no changes or edits are made and the original work is properly cited (including links to both the formal publication through the relevant DOI and the license). See: https://creativecommons.org/licenses/by-nc-nd/4.0/.

\section{References}

1. Davis WA, Knuiman M, Kendall P, et al. Glycemic exposure is associated with reduced pulmonary function in type 2 diabetes: the Fremantle Diabetes Study. Diabetes Care 2004;27:752-7.

2. Enomoto T, Usuki J, Azuma A, et al. Diabetes mellitus may increase risk for idiopathic pulmonary fibrosis. Chest 2003;123:2007-11.

3. Zhao W, Chen GM, Sun B, et al. Effects of liraglutide on the expression of local renin-angiotensin system, transforming growth factor- $\beta 1$ and collagen type III in pulmonary tissue of diabetic rats. National Medical Journal of China 2014;94:459-63.

4. Zhao W, Jiang LJ, zhu MY, et al. Effects of rosiglitazone treatment on TGF- $\beta 1 /$ Smad signaling pathways in Otsuka Long-Evans Tokushima Fatty rat lungs. Acta Anatomica Sinica 2011;42:226-31.

5. Park CW, Kim HW, Ko SH, et al. Long-term treatment of glucagon-like peptide-1 analog exendin-4 ameliorates diabetic nephropathy through improving metabolic anomalies in $\mathrm{db} /$ db mice. J Am Soc Nephrol 2007;18:1227-38.

6. Kang BY, Park KK, Green DE, et al. Hypoxia mediates mutual repression between microRNA-27a and PPAR $\gamma$ in the pulmonary vasculature. PLoS One 2013;8:e79503.

7. Wang J, Song Y, Zhang Y, et al. Cardiomyocyte overexpression of miR-27b induces cardiac hypertrophy and dysfunction in mice. Cell Res 2012;22:516-27.

8. Zhao W, Song XC, Jiang LJ, et al. The changes of expression of $\alpha$-smooth muscle actin in lung of spontaneous type 2 diabetes rats. China Medicine 2011;6:541-3.

9. Miao XY, Gu ZY, Liu P, et al. The human glucagon-like peptide-1 analogue liraglutide regulates pancreatic betacell proliferation and apoptosis via an AMPK/mTOR/ P70S6K signaling pathway. Peptides 2013;39:71-9.

10. Ben-Shlomo S, Zvibel I, Shnell M, et al. Glucagon-like peptide-1 reduces hepatic lipogenesis via activation of AMP-activated protein kinase. J Hepatol 2011;54:1214-23.

11. Pitocco D, Fuso L, Conte EG, et al. The diabetic lung--a 
new target organ? Rev Diabet Stud 2012;9:23-35.

12. García-Sancho Figueroa MC, Carrillo G, Pérez-Padilla $\mathrm{R}$, et al. Risk factors for idiopathic pulmonary fibrosis in a Mexican population. A case-control study. Respir Med 2010;104:305-9.

13. Weynand B, Jonckheere A, Frans A, et al. Diabetes mellitus induces a thickening of the pulmonary basal lamina. Respiration 1999;66:14-9.

14. Hyldgaard C, Hilberg O, Bendstrup E. How does comorbidity influence survival in idiopathic pulmonary fibrosis? Respir Med 2014;108:647-53.

15. Forgiarini LA Jr, Kretzmann NA, Porawski M, et al. Experimental diabetes mellitus: oxidative stress and changes in lung structure. J Bras Pneumol 2009;35:788-91.

16. Gumieniczek A, Hopkala H, Wojtowicz Z, et al. Changes in antioxidant status of lung tissue in experimental diabetes in rabbits. Clin Biochem 2002;35:147-9.

17. Singh S, Bodas M, Bhatraju NK, et al. Hyperinsulinemia adversely affects lung structure and function. Am J Physiol Lung Cell Mol Physiol 2016;310:L837-45.

18. Zhao W, Zhang H, Xie Y, et al. The pathological changes of ultrastructure in bronchial mucosa of type 2 Diabetic patients. Acta Anatomica Sinica 2006;37:685-8.

19. Zhang H, Bai JW, Yu ZT, et al. The changes and its clinical significance of ultrastructure in lungs of type 2 Diabetic patients. Acta Anatomica Sinica 2005;36:656-9.

20. Choi JH, Jin SW, Choi CY, et al. Capsaicin Inhibits

Cite this article as: Liu J, Li X, Lu S, Zheng X, Zhang X, Zhao W. Glucagon-like peptide-1 (GLP-1) improved diabetic lung fibrosis via AMPK and microRNA-27a (miR-27a). Ann Transl Med 2021;9(6):492. doi: 10.21037/atm-21-869
Dimethylnitrosamine-Induced Hepatic Fibrosis by Inhibiting the TGF- $\beta 1 /$ Smad Pathway via Peroxisome Proliferator-Activated Receptor Gamma Activation. J Agric Food Chem 2017;65:317-26.

21. Calvier L, Boucher P, Herz J, et al. LRP1 Deficiency in Vascular SMC Leads to Pulmonary Arterial Hypertension That Is Reversed by PPAR $\gamma$ Activation. Circ Res 2019;124:1778-85.

22. Liu J, Zhao W, Song XC, et al. Effects of Rosiglitazone on Transforming Growth Factor- $\beta 1$ and its Signaling Pathway Genes Expressions in Pulmonary Tissue of Otsuka LongEvans Tokushima Fattv Rats. Chinese Journal of Prevention and Control of Chronic Diseases 2012;20:271-3.

23. Tang X, Wang Y, Guo X, et al. Effects of glucagon like peptide-1 treatment on the alveolar capillary basal lamina in Otsuka Long-Evans Tokushima Fatty rats. Journal of Peking University (Health Sciences) 2008;40:178-80.

24. Li Z, Ni CL, Yao Z, et al. Liraglutide enhances glucose transporter 4 translocation via regulation of $\mathrm{AMP}$-activated protein kinase signaling pathways in mouse skeletal muscle cells. Metabolism 2014;63:1022-30.

25. Wu J, Liu S, Yuan ZW, et al. MicroRNA-27a Suppresses Detrusor Fibrosis in Streptozotocin-Induced Diabetic Rats by Targeting PRKAA2 Through the TGF- $\beta 1 / \mathrm{Smad} 3$ Signaling Pathway. Cell Physiol Biochem 2018;45:1333-49. 